\title{
O QUE PENSAM AS EQUIPES DIRETIVAS ESCOLARES SOBRE O ATENDIMENTO EDUCACIONAL ESPECIALIZADO (AEE)
}

\author{
Neusa Denise Marques de Oliveira - (https://orcid.org/0000-0001-5425-4055) * \\ Instituto Federal Catarinense, Camboriú, Santa Catarina, Brasil \\ Aliciene Fusca Machado Cordeiro - (https://orcid.org/0000-0001-6778-5285) ** \\ Educação da Universidade da Região de Joinville, Bom Retiro,Santa Catarina, Brasil
}

RESUMO: O artigo apresenta um estudo que teve por objetivo investigar as compreensões das equipes diretivas escolares sobre o serviço de Atendimento Educacional Especializado. Como instrumento de coleta de dados, utilizou-se um questionário. Participam da pesquisa sete diretores(as), oito supervisores(as) e sete orientadores(as) de sete escolas de uma cidade do Estado de Santa Catarina, totalizando 22 participantes. A análise de conteúdo foi utilizada para analisar as compreensões das sete Equipes Diretivas (ED). Os resultados demonstraram que a maioria dos participantes tem uma compreensão sobre o AEE focada no público alvo da Educação Especial. Assim, o Atendimento Educacional Especializado parece ser entendido pelas equipes diretivas como um serviço individualizado, setorizado e com pouca interlocução entre os profissionais da escola.

Palavras-chave: Gestão escolar; Equipe diretiva escolar; Educação Especial; Atendimento Educacional Especializado.

\section{WHAT DO SCHOOL MANAGEMENT TEAMS THINK ABOUT SPECIALIZEDEDUCATIONAL ASSISTANCE?}

ABSTRACT: This study aimed to investigate the understandings of school management teams about the Specialized Educational Assistance service. As a data collection instrument, a questionnaire was used. The participants in

\footnotetext{
* Neusa Denise Marques de Oliveira, possui Mestrado em educação pela Universidade da Região de Joinville - UNIVILLE, Especialização em Psicopedagogia e graduação em Pedagogia/habilitação em orientação educacional. Atualmente é pedagoga/orientadora educacional, coordenadora do Núcleo Pedagógico no Instituto Federal Catarinense - Campus Camboriú, e integrante da equipe multidisciplinar do Atendimento Educacional Especializado. Integrante do Grupo de Estudos e Pesquisas sobre o Trabalho e a Formação Docente (GETRAFOR). E-mail:<ndmoliveira@gmail.com >.

* * Aliciene Fusca Machado Cordeiro, possui doutorado em Educação (Psicologia da Educação) pela Pontifícia Universidade Católica de São Paulo (2006), mestrado em Educação (Psicologia da Educação) pela Pontifícia Universidade Católica de São Paulo (2001) e graduação em Psicologia pela Pontifícia Universidade Católica de Campinas (1995). É coordenadora do Grupo de Estudos e Pesquisas sobre 0 Trabalho e a Formação Docente (GETRAFOR) e professora- pesquisadora do Mestrado em Educação da Universidade da Região de Joinville - UNIVILLE. E-mail:< aliciene_machado@hotmail.com >
} 
this research were seven principals, eight supervisors and seven counselors from seven schools in a city in the state of Santa Catarina, totaling 22 participants. Content analysis was used to analyze the understandings of the seven Directive Teams. The results demonstrated that the majority of participants have an understanding about Specialized Educational Assistance focused on the target audience of Special Education. The Specialized Educational Assistance seems to be understood by the management teams as an individualized service, sectored and with little interlocution among other professionals of the school.

Keywords: School management; School management team; Special education; Specialized Educational Assistance.

\section{INTRODUÇÃO}

No Brasil, nos últimos anos, vem crescendo o discurso em relação à Educação Especial (EE), mais especificamente com enfoque inclusivo, que emergiu em meados dos anos de 1990, por meio da incorporação das orientações internacionais abordadas na Declaração Mundial sobre Educação para Todos (UNICEF, 1990), bem como, com a adesão às orientações da Declaração de Salamanca (UNESCO, 1994), nas formulações das políticas brasileiras (MELETTI e BUENO, 2011).

Nessa perspectiva, para Pletsch (2011), as diretrizes educacionais que seguem os pressupostos internacionais, incorporam como sustentação de seu discurso os direitos educacionais e sociais das pessoas público-alvo da EE, prometendo a elas a equidade de oportunidades, o que não significa assegurar igualdade de condições. Sobre isso, ainda, a autora reitera que:

[...] esse tipo de concepção reconhece os direitos individuais, mas não se responsabiliza pelas condições sociais que determinam as desigualdades socioeconômicas e de poder. Essa perspectiva acaba responsabilizando o sujeito pelo seu "sucesso" ou "fracasso" no emprego, na escola e em outros âmbitos da vida social. Em outras palavras, enquanto ampliam-se as políticas focalizadas de inclusão, continua-se excluindo o sujeito, pois não se oferece condições efetivas para que ocorra a integração e a mobilidade social no sistema econômico vigente. (PLETSCH, 2011, p.39)

A exposição crítica e reflexiva da autora em relação às proposições das políticas educacionais leva a um questionamento que diz respeito a como as diretrizes da Educação Especial e, mais especificamente, o Atendimento Educacional Especializado, vem se constituindo e se configurando atualmente, nas escolas brasileiras. 
Nessa perspectiva, Freitas (2002) adverte que ao realizar uma análise acerca da escola pública, é preciso levar em conta as pressões econômicas, políticas e sociais postas a ela pelo sistema capitalista. Pressões essas que se traduzem em políticas públicas impregnadas de pressupostos neoliberais e colocadas em funcionamento com o objetivo de "reduzir custos econômicos, sociais e políticos, sem alterar a essência seletiva da escola, resultando em maior número de repetência e evasão, criando um campo de exclusão subjetiva" (FREITAS, 2002, p. 299). Isso pode significar que a escola pública que se conhece parece não estar sendo inclusiva para a maioria de seus estudantes e não somente para os que são denominados públicoalvo da EE. Nessa direção, o autor enfatiza ainda que:

[..] quanto mais se falou em inclusão mais se legitimou a exclusão social prévia à escolarização, por um mecanismo dissimulatório de inclusão formal na escola que transmutou a exclusão escolar objetiva (repetência, evasão) em exclusão escolar subjetiva (autoexclusão entre ciclos, "opções" por trilhas de progressão menos privilegiadas, trânsito formal sem domínio real), a partir dos horizontes e das possibilidades de classe previamente interiorizados pelas condições objetivas de cada classe na sociedade. (FREITAS, 2002, p. 310)

Ante o exposto, Kassar e Meletti (2012) ressaltam, apoiadas em Di Giovanni (2009), que a Política Nacional de Educação Especial na Perspectiva da Educação Inclusiva, como qualquer política pública, não é assimilada automaticamente e de forma homogênea pelos sistemas de ensino e, por conseguinte, por suas escolas. Isso porque, como expôs Michels (2004, p. 44):

[...] os sujeitos envolvidos entendem as indicações políticas de maneira distinta, conforme suas vivências, seus interesses, sua organização profissional, entre outros. Cada instituição educacional acaba por "implementar" as políticas à sua maneira.

Em meio a essas reflexões supracitadas, pode-se perceber a importância da atuação crítica e reflexiva da equipe diretiva juntamente com a comunidade escolar, no que tange as políticas educacionais, em destaque aqui a Política Nacional Educação Especial na Perspectiva Inclusiva - PNEE-EI e o Atendimento Educacional EspecializadoAEE. É importante que a equipe diretiva compreenda o contexto histórico, econômico, político e social em que está inserida assim como, quais pressupostos permeiam tais políticas, buscando formas de constituir um fazer pedagógico que possa contribuir com um efetivo processo de escolarização de todos os estudantes.

Esclarece-se, nesse sentido, que dentre os profissionais da educação envolvidos na implementação e viabilização das proposições 
da atual política de Educação Especial, encontra-se a equipe diretiva escolar, que segundo Vasconcellos (2013, p. 51), é "composta pelo Diretor(a), Supervisor(a)/Coordenador(a) Pedagógico(a) e Orientador(a) Educacional", profissionais que desempenham um papel de referência na escola e podem contribuir de modo significativo para o processo de escolarização dos estudantes ao atuarem de forma articulada no espaço escolar.

Com o intuito de conhecer as pesquisas que abordam a temática da gestão escolar/equipe diretiva escolar em relação à Educação Especial/ AEE, realizou-se uma pesquisa em duas bases de dados: 1) Biblioteca Digital Brasileira de Teses e Dissertações - BDTD e, 2) Banco de Teses e Dissertações da Coordenação de Aperfeiçoamento de Pessoal de Nível Superior - CAPES. Com isso, optou-se por utilizar descritores relacionados ao tema proposto, como "gestão escolar e Educação Especial", como referência para listar a produção científica na área de Educação, sendo que as expressões foram pesquisadas no campo "palavras-chave". No total, foram encontrados onze (11) trabalhos sobre a temática no período considerado (2008 a 2017).

O resultado da pesquisa demonstrou uma baixa quantidade de trabalhos que abrangem a temática, revelando a gestão escolar e a Educação Especial como um campo de estudos e pesquisas que vem sendo paulatinamente explorado.

Dos onze trabalhos encontrados, destacaram-se três para apresentar neste artigo, a saber: Rocha (2016), Silveira (2009) e Santos (2011).

Para iniciar a apresentação optou-se pela pesquisa mais recente, empreendida por Rocha (2016), que buscou investigar "as mudanças decorrentes da efetivação das diretrizes da Política Nacional de Educação Especial na Perspectiva da Educação Inclusiva na gestão da educação especial nos municípios da Área Metropolitana Norte de Curitiba" (ROCHA, 2016, p. 9). A autora ressaltou que o estado do Paraná assume diretrizes político-administrativas divergentes do governo federal em relação à política de educação especial. De acordo com a autora, tal especificidade se traduz na menor "taxa de inclusão no ensino regular (50\%) no estado do Paraná, em relação à média nacional, na oferta do AEE coexistir em salas de recursos multifuncionais e em instituições filantrópicas e na ampliação de grupos que compõem o público-alvo da educação especial”. (ROCHA, 2016, p. 09). Os estudos de Silveira (2009) e Santos (2011), por sua vez, se debruçaram sobre o papel da gestão escolar na constituição de uma escola inclusiva, tendo 
como foco os profissionais que constituem a equipe diretiva escolar, ou seja, o diretor, o supervisor, e o orientador educacional.

$\mathrm{Na}$ pesquisa de Silveira (2009), uma tese de doutorado, a autora empreendeu uma intervenção e acompanhamento de uma escola por um período de 28 meses. O estudo buscou evidenciar a atuação e concepções da equipe gestora da escola em relação à educação inclusiva e aplicar estratégias de acompanhamento, visando à transformação das práticas de gestão, assim como, possibilitar reflexões sobre as concepções de educação especial existentes. Contudo, a autora destacou que as transformações ocorridas na escola não romperam totalmente com os padrões de ensino homogêneos. Além disso, a rotatividade dos professores na escola pesquisada se constituiu em grave problema apesar de não ser específico da escola pesquisada e sim da Rede Municipal como um todo. Tal rotatividade tem como um dos seus motivos a falta de condições adequadas de trabalho. Outro fato evidenciado pela autora é a urgência de formação para os gestores escolares e professores que contemple a temática da Educação Especial.

O estudo de Santos (2011) se propôs a evidenciar as ações desenvolvidas pela gestão escolar (diretor (a), vice-diretor(a) e coordenador(a) pedagógico) na constituição do serviço de Educação Especial na escola. A autora percebeu que a efetivação da Educação Especial no âmbito da escola pesquisada ainda se mostrava um desafio, uma vez que os gestores pesquisados não tinham definido o conceito e os princípios que orientariam tal proposta de educação especial, bem como, "apresentaram práticas de gestão escolar para a Educação Especial pontuais, isoladas e não estando fundamentadas, organizadas ou planejadas nas diretrizes gerais da escola" (SANTOS, 2011, p. 79).

A partir das análises das pesquisas de Rocha (2016), Silveira (2009) e Santos (2011) realizadas em diferentes estados e municípios brasileiros, pode-se perceber que a Política de Educação Especial na Perspectiva Inclusiva vem sendo apreendida e implementada de formas diferentes, isso porque, como ressaltou Michels (2006), a escola vai se constituindo e organizando no embate entre seu cotidiano e as proposições políticas. Além disso, cada escola está inserida em um contexto social, político, cultural e econômico que se expressa nas relações e na organização escolar.

As referidas pesquisas demonstraram ainda, dentre outros fatores, uma fragilidade em comum, que diz respeito à necessidade de um aprofundamento teórico sobre a temática educação especial para os gestores escolares e professores.

Nesse sentido, concorda-se com Rocha (2016, p. 148), ao enfatizar que "o momento no qual vive o Brasil, aponta para a 
necessidade de estudos sobre as políticas em ação, de como essas políticas têm sido traduzidas no contexto da prática, compreender seus efeitos e também suas contradições".

Assim, entende-se que identificar como uma política nacional está se realizando em âmbito local sinaliza, em parte, uma forma de contribuir com a produção de conhecimentos sobre os apoios ofertados aos estudantes considerados público alvo da Educação Especial, ${ }^{1}$ e, principalmente, de indicar ao município pesquisado como esse serviço vem se configurando nas escolas, a partir dos dizeres dos integrantes das equipes diretivas, entendidas neste estudo como protagonistas na implementação e viabilização do AEE na escola.

Ante o exposto, definiu-se apresentar um estudo que teve por objetivo investigar as compreensões das equipes diretivas escolares sobre o serviço de Atendimento Educacional Especializado. A seguir, será abordada a metodologia deste estudo, explicitando a base epistemológica, a abordagem e o tipo de pesquisa, bem como o instrumento utilizado na coleta de dados e os principais autores que fundamentaram o processo de análise. Por conseguinte, será realizada uma apresentação dos participantes desta pesquisa e em seguida inicia-se a análise e discussão dos dados sobre o que pensam as equipes diretivas escolares sobre o AEE. Por fim, apresentam-se as considerações finais.

\section{METODOLOGIA}

Este estudo está fundamentado em uma visão de homem e sociedade alicerçada em uma base epistemológica materialista histórica e dialética, que "[...] percebe os sujeitos como históricos, datados, concretos, marcados por uma cultura, como criadores de ideias e consciência que, ao produzirem e reproduzirem a realidade social são, ao mesmo tempo produzidos e reproduzidos por ela" (FREITAS, 2002, p. 22). A abordagem utilizada foi a qualitativa, que segundo Gatti e André (2010), privilegia os sentidos e significados atribuídos pelos sujeitos às suas vivências.

Utilizou-se como instrumento de coleta de dados um questionário, contendo perguntas abertas e fechadas.

Para a seleção dos participantes, estabeleceram-se quatro critérios de inclusão, nos quais a equipe diretiva deveria:

1) ser composta por diretor(a) escolar, supervisor(a)/coordenador(a) pedagógico e orientador(a) educacional;

2) atuar na Rede Municipal de Ensino pesquisada; 
3) atuar em escola com estudantes público-alvo da Educação Especial;

4) ter o questionário respondido por todos os seus integrantes.

No total foram aplicados 36 questionários, sendo 32 respondidos, porém, apenas 22 foram considerados válidos de acordo com os critérios de inclusão desta pesquisa.

Nessa direção, selecionados os participantes a pesquisa contou com 22 integrantes de sete equipes diretivas, sendo sete diretores(as), sete orientadores(as) e oito supervisores (as), que trabalham em sete escolas da Rede Municipal de Ensino de uma cidade do Estado de Santa Catarina.

De posse dos 22 questionários, seguiu-se com a transcrição das respostas para uma planilha de Excel, organizando-as por questão.

A identificação dos respondentes foi realizada por meio de códigos formados por letras e números. As escolas foram representadas por números de 1 a 7 e os profissionais das equipes diretivas foram

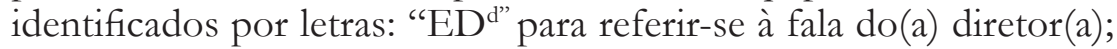
"ED", do(a) supervisor(a); e "ED", do(a) orientador(a), exemplo, "ED1" refere-se a(o) Supervisor(a) da Escola 1; "ED4d", ao(a) Diretor(a) da Escola 4; e assim por diante.

A análise de dados inspirou-se na análise de conteúdo (BARDIN, 1977; FRANCO, 2012). Segundo Franco (2012), na análise de conteúdo considera-se, além das mensagens implícitas e explícitas, o contexto histórico no qual seus produtores estão inseridos.

Nesse sentido, buscaram-se possíveis recorrências, contradições e complementaridades, nas falas dos participantes, a fim de constituir os primeiros indicadores de análise. A partir desses, foi criada a categoria de análise denominada "Compreensões das equipes diretivas Escolares sobre o Atendimento Educacional Especializado", a qual será abordada neste estudo. Assim, para algumas questões abertas, optou-se por realizar uma análise com o apoio de quadros com as respostas mais recorrentes dos integrantes das equipes diretivas, procurando ilustrar e focalizar a articulação das respostas obtidas com as teorias estudadas.

\section{PARTICIPANTES DA PESQUISA}

Apresentando brevemente os 22 profissionais das equipes diretivas escolares que participaram desse estudo, 17 identificaramse com o gênero feminino e cinco com o masculino. Em relação à carga horária, todos responderam que trabalham 40 horas semanais, nas escolas em que atuam.

No que tange ao ingresso no cargo, para cada função observouse um processo diferente. Todos os diretores(as) ingressaram na 
função por meio de indicação, enquanto a maioria dos orientadores(as) e supervisores(as) teve seu ingresso por meio de concurso público. Somente um supervisor(a) informou ter ingressado por meio de convite e um(a) orientador(a) por meio de um processo seletivo, diferenciado do concurso público.

Em relação ao ingresso do diretor na função, identificou-se que a prática da eleição, em detrimento da indicação hoje praticada, pode ser um caminho para aproximar ainda mais as escolas municipais dos princípios de democratização e participação na Rede Municipal de Ensino pesquisada.

Paro (2003, p. 124) adverte a esse respeito que a introdução da eleição nas escolas não se dá de forma harmoniosa e, "como todo instrumento de democracia, não está livre dos conflitos e tensionamentos". Contudo, constitui-se como uma forma de permitir que um número maior de pessoas da comunidade escolar se envolva nos processos decisórios e na gestão da escola. O ingresso na função de direção por meio de indicação pode corroborar para fragilizar a constituição de trabalhos conjuntos, dado que há, entre outros aspectos, uma rotatividade nessa função que independe das escolhas da comunidade escolar, bem como uma insegurança na permanência no cargo.

Concluindo a apresentação dos participantes, em relação ao tempo de atuação, percebeu-se que a maioria (14 de 22 respondentes) se encontra em um momento inicial (até três anos) na função ocupada na escola em que hoje trabalha, se configurando em um dos desafios postos às equipes diretivas na implementação do AEE, visto que em cada escola há uma cultura organizativa instituída, que precisa ser conhecida, debatida, para então ser mantida ou se necessário transformada. Compreende-se, ainda, que para atuar nessas funções é necessário um aprofundamento teórico que permita uma leitura crítica acerca das políticas e normativas educacionais vigentes, de modo que possam discuti-las junto ao coletivo escolar, antes de sua implementação.

A partir dessa breve contextualização dos integrantes das equipes diretivas, inicia-se, agora, a apresentação e discussão dos dados a respeito do que pensam as equipes diretivas sobre o AEE, no âmbito escolar.

\section{COMPREENSÕES DAS EQUIPES DIRETIVAS ESCOLARES SOBRE 0 ATENDIMENTO EDUCACIONAL ESPECIALIZADO}

Procurou-se discutir, neste estudo, as compreensões das equipes diretivas escolares sobre o Atendimento Educacional Especializado, focalizando o serviço em si e o público-alvo da EE. 
Para tanto, inicia-se, primeiramente, com a análise e discussão dos dados que dizem respeito ao funcionamento do serviço de AEE nas sete escolas pesquisadas, conforme se apresenta no Quadro 1:

QUADRO 1. Situando o Atendimento Educacional Especializado nas escolas pesquisadas ${ }^{2}$

\begin{tabular}{|c|c|c|c|c|c|c|c|}
\hline & ED1 & ED2 & ED3 & ED4 & ED5 & ED6 & ED7 \\
\hline Possui Sala de Recursos Multifuncionais & $\mathrm{X}$ & $\mathrm{X}$ & & $X$ & & & $\mathrm{X}$ \\
\hline Possui Professor de AEE & & $x$ & & $x$ & & & \\
\hline $\begin{array}{l}\text { Escola - polo e atende estudantes público alvo da EE } \\
\text { de outras duas escolas }\end{array}$ & & $x$ & & & & & \\
\hline Oferta AEE na própria escola & & $x$ & & $\mathrm{X}$ & & & \\
\hline Encaminha os estudantes para o AEE em outra escola & & & & & $\mathrm{x}$ & & \\
\hline $\begin{array}{l}\text { Estudantes público-alvo da EE são acompanhados } \\
\text { pelo Professor da Sala Comum e pelo Monitor de } \\
\text { Inclusão da sala comum. }\end{array}$ & & & $x$ & & & & $x$ \\
\hline $\begin{array}{l}\text { Não possui estrutura física e recursos humanos } \\
\text { para oferecer o AEE e não apresenta indícios de } \\
\text { encaminhamento para outras escolas. }\end{array}$ & & & & & & $x$ & \\
\hline $\begin{array}{l}\text { Possui estrutura física, mas não o professor } \\
\text { especializado. E não apresenta indícios de } \\
\text { encaminhamento para outras escolas. }\end{array}$ & $x$ & & & & & & \\
\hline
\end{tabular}

Fonte: Primária (2016).

É possível constatar, a partir dos dados expressos no Quadro 1 acima, que, das sete escolas pesquisadas, quatro possuem Sala de Recursos Multifuncionais (SRM) localizada em seu espaço físico. Das quatro (ED1, ED2, ED4 e ED7) que as possuem, apenas duas (ED2 e ED4) contam com professor de AEE e ofertam esse serviço na própria escola; as outras duas, apesar de possuírem o espaço físico para realização do AEE, não o realizam (ED1) ou apresentam um entendimento de que o AEE acontece na sala comum, a partir do acompanhamento do professor e do monitor de inclusão ${ }^{3}$ (ED3 e ED7).

No entanto, ressalta-se aqui a situação do AEE nas escolas em que atuam as equipes diretivas ED1 e ED6. A ED1 ${ }^{\text {s }}$ apesar de possuir a SRM, não conta com o profissional especializado e de acordo com os dizeres do(a) supervisor(a), [...] "nenhum destes alunos possui 
atendimento especializado". Já a ED6, além de não possuir estrutura física e recursos humanos para oferecer o AEE, não apresenta indícios de encaminhamento para outras escolas. E, conforme o relato do(a) diretor(a) ED6 "“[...] infelizmente [estes estudantes público-alvo da EE] não são atendidos". O que possibilita inferir que o serviço de AEE não vem sendo realizado pela escola, ainda que ela tenha estudantes público-alvo da Educação Especial matriculados, denotando ausência desse serviço, que por sua vez, revela as "tensões entre o legal documentado [e] sistemática já estabelecida, vivida no espaço escolar" (FUCK, 2014, p. 147). Convergindo com a discussão, Freitas (2011, p. 227) enfatiza que:

[...] o desafio da escola comum não é somente com a inclusão de pessoas com deficiências, mas o de uma transformação na sua totalidade pedagógica, tendo em vista as diferenças de todos os alunos. Daí os inúmeros desafios frente às contradições que demarcam as diferentes realidades do contexto nacional se acreditarmos numa educação como processo de mudança e de transformação.

Assim, evidenciar que das sete equipes diretivas pesquisadas, quatro possuem Salas de Recursos Multifuncionais implantadas em suas respectivas escolas, e dessas, somente duas (ED2 e ED4) estão em funcionamento, permite identificar um ponto de atenção, acerca de como são compreendidas as necessidades e o processo de escolarização desses estudantes nas escolas da Rede Municipal de Ensino pesquisadas. Ou seja, as que não possuem a SRM e o professor especializado, com exceção a ED5, parecem não se organizar de formas diferentes para assegurar os apoios necessários à aprendizagem dos estudantes considerados da EE, como por exemplo, encaminhá-los para as escolas que possuem o AEE ou oferecer outros tipos de apoios pedagógicos aos estudantes.

É importante ressaltar que o espaço da Sala de Recursos Multifuncionais e o professor especializado, por si só, não asseguram ao estudante público-alvo da Educação Especial uma melhoria em seu processo de escolarização. Nesse sentido, concorda-se com Effgen (2011, p. 158), quando ressalta que, ao discutir acerca da SRM e do AEE, é preciso considerar "[...] que esse espaço e esse dispositivo configuram-se como uma rede de apoio à sala de aula regular, mas o centro do processo ensino-aprendizagem é a sala regular".

Contudo, parece haver um entendimento por parte da maioria das equipes diretivas pesquisadas, que o AEE se limita ao espaço da SRM. Esse entendimento, por sua vez, pode revelar uma carência por parte das equipes diretivas de um aprofundamento teórico sobre a área da Educação Especial. Uma vez que a forma como a política e as 
diretrizes da Educação Especial parecem ser interpretadas pelas equipes diretivas e como o serviço vem se materializando no contexto escolar de forma setorizada, pode sinalizar que há uma carência no entendimento de que Educação Especial está contida na Educação [Regular]. O AEE é um dos apoios para o estudante público-alvo da EE e também, à comunidade escolar, e precisa estar contemplado nas diretrizes da escola.

As pesquisas como as empreendidas por Silveira (2009), Boaventura (2008) e Santos (2011), também sinalizaram a necessidade de formação para os gestores escolares e professores que abordasse a temática da Educação Especial.

Acredita-se que as equipes diretivas possuem um papel de referência na escola, na organização e implementação do serviço de AEE, juntamente com a comunidade escolar, considerando a necessidade desse serviço e sua forma de atuação para auxiliar a permanência e aprendizagem dos estudantes público-alvo da EE, por meio de um processo de escolarização que leve em conta suas singularidades, potencialidades e sobretudo a garantia do direito de aprender.

Nessa perspectiva, Rossato e Leonardo (2012, p. 113) convidam a refletir:

[...] ao se considerar a educação escolar como fundamental para a apropriação da cultura produzida, cabe questionar sobre a educação e dentro desta, a educação especial, discutindo sobre as formas e condições de ensino oferecidas às pessoas com deficiência e às pessoas que aprendem diferentemente por nem sempre lhes possibilitarem o aprendizado escolar. Condições de ensino essas, que podem concentrar nelas estigma de fracasso e de incapacidade, de maneira a não viabilizar e não cumprir com a sua função de socialização do conhecimento elaborado, sistematizado.

Nessa direção, Martins (2001) contribui com a discussão ao reiterar que ao se defender o acesso e o direito de aprender dos estudantes público-alvo da EE na escola regular, "além dos aspectos legais que a respaldam, é fundamental analisar que esta escola é um direito de todos os cidadãos”. (MARTINS, 2001, p. 30)

Diante das discussões iniciais que puderam ser realizadas com base na situação do AEE em cada escola pesquisada, segue-se agora para a análise das respostas das equipes diretivas acerca de sua compreensão sobre o AEE.

Dos 22 participantes, 15 demonstraram uma compreensão sobre o AEE focado no público alvo da Educação Especial; quatro, no local de atendimento (Sala de Recursos Multifuncionais); e, três, no processo de escolarização como um todo. Com exceção desses três últimos foi possível perceber que a maioria dos participantes 
demonstrou uma compreensão desarticulada, em que se foca no estudante com deficiência ou na SRM de forma isolada, privilegiando assim, um dentre os diversos aspectos que envolvem esse serviço.

Observou-se, nos dizeres dos participantes deste estudo, uma compreensão sobre o AEE com foco no público-alvo desse serviço. Esse entendimento representa a maior parte das respostas das equipes diretivas. Ao especificarem quem compõe esse público-alvo, percebe-se que a principal referência feita por eles foi ao estudante com deficiência, seguida de estudantes com dificuldades e distúrbios. As falas a seguir ilustram esse entendimento:

$\mathrm{ED} 3^{\mathrm{d}} \mathrm{S}$ ão alunos com dificuldade, que recebem atendimento especializado.

$\mathrm{ED} 2^{\circ}$ É um atendimento individualizado [para os estudantes público-alvo da EE], trabalhando suas habilidades.

ED4s Atendimento para auxiliar alunos com deficiência $e$ distúrbios. (grifo nosso)

Essas falas, que surgiram a partir da questão "Qual é a sua compreensão sobre o AEE?", podem ser associadas aos dizeres proferidos pelos integrantes das equipes diretivas quando perguntados sobre "Quem são os estudantes público-alvo da Educação Especial?". O Quadro 2, a seguir, indica quais foram as suas respostas:

QUADRO 2. Recorrências sobre o público-alvo da EE nos dizeres das equipes diretivas escolares pesquisadas

\begin{tabular}{|l|c|}
\hline \multicolumn{1}{|c|}{ Categorias } & Recorrências \\
\hline Deficiência & 18 \\
\hline Transtornos & 7 \\
\hline Altas Habilidades/Superdotação & 3 \\
\hline Laudo Médico & 2 \\
\hline Dificuldades especificas/especiais & 2 \\
\hline Distúrbios & 1 \\
\hline Necessidades especiais & 1 \\
\hline Déficit de atenção & 1 \\
\hline
\end{tabular}

Fonte: Primária (2016). 
Considera-se importante, em primeiro lugar, elucidar que delimitar o público-alvo da Educação Especial, para além de definir para quem o serviço de AEE é destinado, consiste em um termo da lógica que marca a diferença entre os estudantes. Conforme explicou Veiga-Neto (2011, p. 110-111, grifo nosso):

[...] a própria lógica de dividir os estudantes em classes - por níveis cognitivos, por aptidões, por gênero, por idades, por classes sociais etc. - foi um arranjo inventado para, justamente, colocar em ação a norma, através de um crescente e persistente movimento de, separando o normal do anormal, marcar a distinção entre normalidade e anormalidade.

É preciso considerar, inicialmente, que a categorização do público-alvo da Educação Especial definida na PNEE-EI (2008), como sendo pessoas com deficiência, transtornos globais do desenvolvimento e altas habilidades/superdotação, é uma constituição histórica recente.

Desse modo, quando analisadas as respostas mais recorrentes dos integrantes das equipes diretivas contidas no Quadro 2 acima, é possível evidenciar que o termo utilizado com mais frequência por estes, para se referirem ao público-alvo do AEE, foi "deficiência".

Nesse sentido, questiona-se: quem e/ou o que se perde de vista, quando o foco está no estudante com deficiência? Podese dizer que ao restringir o público alvo da $\mathrm{EE}$ ao estudante com deficiência, incorre-se no risco de se distanciar de uma compreensão sobre os transtornos globais do desenvolvimento e altas habilidades, [...] "já que representam realidades complexas que necessitam de compreensão explícita de suas características para que possam ser oferecidos os apoios necessários". (ARAÓZ, 2010, p. 15).

Ante o exposto, questiona-se se seriam esses estudantes com transtornos globais do desenvolvimento e altas habilidades/ superdotação, pouco citados nos dizeres dos integrantes das equipes diretivas escolares, uma minoria matriculada em sala de aula comum nas escolas brasileiras? Para responder a esse questionamento, recorreu-se aos dados publicados no Censo Escolar (MEC/INEP, 2015), a fim de conhecer o número total de estudantes público-alvo da EE matriculados nas escolas brasileiras e em Santa Catarina. Tais informações podem ser conferidas no Quadro 3 que segue: 
QUADRO 3. Distribuição das matrículas por categoria utilizada no Censo Escolar de 2015 (MEC/INEP, 2015), no Brasil e em Santa Catarina.

\begin{tabular}{|l|c|c|}
\multicolumn{1}{c|}{} & \multicolumn{2}{|c|}{$\begin{array}{r}\text { Total de Matrículas na Educação Especial em Classes } \\
\text { Comuns - Ensino Regular e EJA }\end{array}$} \\
\hline \multicolumn{1}{|c|}{ Categoria } & Brasil & Santa Catarina \\
\hline Deficiências & 756.642 & 27.097 \\
\hline $\begin{array}{l}\text { Transtornos Globais do } \\
\text { Desenvolvimento }\end{array}$ & 84.012 & 4.125 \\
\hline Altas Habilidades/Superdotação & 14.166 & 314 \\
\hline
\end{tabular}

Fonte: Formulado a partir dos dados contidos na Sinopse Estatística da Educação Básica. (MEC/INEP, 2015).

Pode-se perceber que, de fato, os estudantes diagnosticados com transtornos globais e com altas habilidades/superdotação são a minoria dos estudantes do público-alvo da EE matriculado nas escolas do Brasil e de Santa Catarina. Ou seja, quando as equipes diretivas pesquisadas recorrem com frequência ao termo "deficiência" para especificar o público-alvo da EE, pode-se dizer que elas falam daquilo que vivenciam em seu cotidiano escolar, por mais que o façam de forma generalizada.

Ressalta-se, nesse sentido, que é preciso atentar para o cuidado de não generalizar os estudantes público-alvo da EE, como sendo apenas os estudantes com deficiência, devido a essa predominância numérica. Generalizar consistiria em uma forma de encobrir a existência dos demais estudantes e, com isso, correr o risco de negar a diversidade que também existe no âmbito do público-alvo da EE. Nessa direção, Vasques (2015, p.118) esclarece que:

[...] a inclusão escolar envolve uma construção compartilhada a partir dos nossos pressupostos a respeito de educação, escola, aluno, [educação especial], infância etc. Tais antecipações ganham significados a partir do contexto, da historicidade e da interpretação dos sujeitos, das políticas públicas educacionais e das instituições envolvidas.

As compreensões supracitadas revelam uma parte (públicoalvo) de um todo (AEE). Falam de um aspecto importante desse serviço de AEE, que diz respeito a para quem ele é ofertado. Contudo, adverte-se para o risco de se tomar a parte pelo todo, isto é, reduzir o AEE ao indivíduo que é público-alvo desse serviço. 
Uma compreensão reducionista pode levar a um entendimento descontextualizado, que deixa de fora da análise outros fatores que compõem o AEE compreendendo em sua necessária articulação com o contexto social, político e econômico vigente; o envolvimento de todos os profissionais da escola na efetivação do AEE, dentre os quais figura a equipe diretiva aqui estudada, a participação da família e da comunidade, e as condições objetivas da escola.

Em relação às condições objetivas, Paro (2016) esclareceu que se referem à infraestrutura física; aos recursos humanos, materiais e pedagógicos, à formação profissional em serviço, ao apoio aos professores, dentre outros fatores. Tais condições podem favorecer ou desfavorecer o processo de escolarização dos estudantes públicoalvo da Educação Especial, bem como o trabalho da equipe diretiva escolar no que tange à implementação e viabilização do AEE.

Simplificar o entendimento do AEE, restringindo-o ao estudante com deficiência, pode indicar que os integrantes das equipes diretivas não compreendem o serviço como aquele que deve contribuir para uma adequação estrutural, pedagógica e cultural, buscando eliminar as barreiras e propiciando a interface entre o professor especializado e o professor da sala comum, com o intuito de favorecer o processo de escolarização e desenvolver a autonomia e independência dos estudantes público-alvo da EE, dentro e fora da escola. Nessa perspectiva, Garcia (2008, p.21) expôs que:

[...] ainda que a implantação de serviços especializados nas redes de ensino signifique um ganho em termos de oferta educacional pública para os alunos com deficiência, é necessário questionar qual o papel exercido por tais serviços e como estão relacionados ao trabalho pedagógico realizado na educação básica.

A compreensão do AEE a partir do seu público-alvo também exige o cuidado de se considerar a dimensão do indivíduo sem responsabilizá-lo unicamente pelo processo de escolarização, uma vez que a culpabilização individual é "[...] uma das estratégias psicossociais mais sutis na tarefa de legitimação da exclusão”. (GUARESCHI, 2011, p. 151)

Compreende-se que direcionar o foco ao estudante também pode sinalizar que o processo de escolarização pode estar acontecendo de maneira precária ${ }^{4}$ nas escolas pesquisadas, de modo que apenas um dos fatores envolvidos está sendo considerado, nesse caso - o estudante, ou de forma mais específica, sua deficiência - quando se trata de oferecer um atendimento que enfoque sua necessidade educacional específica. O caráter ilusório da inclusão nesse estudo se expressa quando o serviço de AEE, para alguns integrantes das equipes diretivas estudadas, não é compreendido a partir de uma perspectiva 
contextualizada, que considere aspectos estruturais, pedagógicos e histórico-culturais, mas se reduz à deficiência do estudante.

Ainda que a maioria dos integrantes das equipes diretivas tenha apresentado um entendimento sobre o AEE com foco em seu público-alvo, alguns deles demonstram uma compreensão sobre o serviço focalizada no local em que é realizado, a Sala de Recursos Multifuncionais, conforme identificado nos dizeres abaixo:

ED1 ${ }^{\mathrm{d}}$ Temos a sala, mas não tem especialista para trabalhar.

ED1 ${ }^{\circ}$ Temos a sala, mas não tem especialista para trabalhar nossos alunos.

ED $6^{s}$ Com relação a nossa unidade de ensino e do município em geral a falta de espaço adequado e profissionais qualificados é de grande expressão. (grifos nossos)

Evidenciou-se que, ao serem questionados acerca de seus entendimentos sobre o AEE, a primeira associação feita pelos participantes foi com um espaço físico: "Temos a sala" e "falta de espaço adequado". O que chama a atenção é que junto a essa primeira associação há uma segunda, relacionada ao profissional especializado. Logo, nos dizeres desses participantes se revela uma imagem do AEE como uma Sala de Recursos Multifuncionais com um professor de AEE, dentro dela.

Essa interpretação expressa nas falas dos participantes deste estudo tem seu fundamento das diretrizes da EE, em destaque aqui, a Resolução no 4/2009 (BRASIL, 2009), que Institui Diretrizes Operacionais para o Atendimento Educacional Especializado na Educação Básica, na qual se pode identificar a ênfase conferida a esses aspectos já no seu art. 1:

[...] os sistemas de ensino devem matricular os alunos com deficiência, transtornos globais do desenvolvimento e altas habilidades/superdotação nas classes comuns do ensino regular e no Atendimento Educacional Especializado (AEE), ofertado em salas de recursos multifuncionais ou em centros de Atendimento Educacional Especializado da rede pública ou de instituições comunitárias, confessionais ou filantrópicas sem fins lucrativos. (BRASIL, 2009, p. 1)

Percebe-se, a partir da citação, que na própria resolução a primeira referência feita ao que é o Atendimento Educacional Especializado no art. 1 é acompanhada do termo "sala de recursos multifuncionais". Nota-se, assim, que essa associação entre AEE e SRM se faz visível não apenas nos dizeres dos integrantes das equipes diretivas, mas também nos documentos oficiais. Os documentos oficiais, desse modo, revelam-se como um dos determinantes na construção dos discursos das equipes diretivas no que diz respeito ao AEE. 
No entanto, França (2008), ao realizar um contrapondo, ressalta que as políticas educacionais não são simplesmente incorporadas à escola por seus profissionais, ao contrário disso, elas são interpretadas, ressignificadas pelos sujeitos que nela atuam. Isso acontece porque os profissionais da educação "são sujeitos históricosociais marcados pelas suas experiências e valores, portanto, podem desempenhar um papel ativo capaz de constituir outros sentidos no processo de implementação das políticas". (FRANÇA, 2008, p. 21)

A partir dessas reflexões, segue-se com as evidências encontradas a partir das análises sobre o que pensam as equipes diretivas no que diz respeito ao serviço de AEE. Observou-se, desse modo, que os participantes, ao expressarem suas compreensões sobre o serviço de AEE com um todo, se remeteram especificamente ao professor especializado e à Sala de Recursos Multifuncionais.

Entretanto, esse enfoque específico demonstra, mais uma vez, o risco de uma compreensão limitada, que toma a totalidade do AEE pela parte do espaço físico em que ele acontece. Essa compreensão, por sua vez, é indicativa de que a segregação que poderia ser minimizada, quem sabe mesmo evitada por meio de estratégias advindas de um serviço como o AEE, parece ainda assombrar os espaços escolares, quando esse serviço é percebido como um local separado para atender ao estudante público alvo da Educação Especial.

Identifica-se, portanto, que as perspectivas excludentes e segregadoras que marcaram a história da Educação Especial parecem encontrar expressão ainda hoje, quando a inclusão, como afirmou Pletsch (2010, p. 60), “[...] ainda é vista como uma responsabilidade setorializada da Educação Especial, e não como um conjunto de medidas que o sistema de ensino como um todo, de maneira interdisciplinar, deveria adotar para efetivar tal proposta". Se até o momento o que se viu por parte da maioria das equipes diretivas foram compreensões fragmentadas, pode-se refletir que hoje é ainda um desafio para elas pensar sobre o AEE a partir de uma perspectiva contextualizada. Ainda que presente na fala da minoria das equipes diretivas, essa perspectiva apareceu nos dizeres de $\mathrm{ED}^{\mathrm{d}} \mathrm{e} \mathrm{ED} 3^{\circ}$, que demonstraram compreender o AEE a partir do processo de escolarização como um todo, expressando um entendimento mais abrangente sobre o serviço:

ED7d "[Compreendo o AEE] como uma inclusão do aluno com deficiência no ensino regular, onde toda escola precisa de mudanças desde o espaço físico como também no seu fazer do cotidiano".

ED3" "[O AEE] deveria ser mais abrangente, aplicado por todos [os profissionais da escola]" (grifos nossos) 
Pode-se perceber que as falas dosintegrantes das equipes diretivas $\left(E D 7^{d}\right.$ e $\left.E D 3^{\circ}\right)$ se distanciam das compreensões individualizadas apresentadas anteriormente, visto que dão sinais de um entendimento de AEE mais amplo. Suas falas remetem à compreensão de que o local do AEE é a escola e, portanto, excede o espaço físico da SRM. Do mesmo modo, indicam que todos os envolvidos, e não apenas o professor especializado, têm um papel importante no processo de escolarização dos estudantes público-alvo da Educação Especial.

Salientam-se, no entanto, algumas expressões importantes contidas nos dizeres de ED7 d e ED3": "precisa" e "deveria". Enquanto $E D 7^{d}$ fala que a escola como um todo "precisa" se transformar para a implementação e viabilização do AEE, ED3 adverte que o AEE "deveria" ser mais abrangente e aplicado por todos os profissionais da escola. Se isto é algo que precisa e deveria ser feito, pode-se inferir que ainda não é uma realidade vivenciada por essas escolas, ou que está em processo de constituição.

Saber o que precisa e deveria ser feito, no entanto, é um passo importante para transformação da realidade. Paulo Freire (1979, p. 40), em um trecho de sua obra "Pedagogia da Esperança", explicou que "a realidade não pode ser modificada, senão quando o homem descobre que é modificável e que ele pode fazê-lo”.

Convergindo com a discussão, Libâneo (2015) esclareceu que as concepções ou compreensões diferentes que habitam a escola exercem um papel fundamental na forma de pensar e na ação de seus profissionais. Uma vez que essas formam a cultura escolar, nesse sentido a equipe diretiva escolar possui um papel de destaque nesse processo.

[...] a partir da interação entre diretores, coordenadores pedagógicos, professores, funcionários e alunos, a escola vai adquirindo, na vivência do dia a dia, traços culturais próprios, vai formando crenças, valores, significados, modos de agir, práticas. [...] Essa cultura própria vai sendo internalizada pelas pessoas e gerando um estilo coletivo de perceber as coisas, de pensar os problemas, de encontrar soluções. (LIBÂNEO, 2015, p. 109)

Pode-se dizer, portanto, que há uma estreita relação entre as formas de compreender o AEE e as práticas a ele relacionadas no contexto escolar. No que tange às equipes diretivas que demonstraram compreender esse serviço de forma mais abrangente e contextualizada, é possível inferir que tal maneira de pensar pode se traduzir em ações como a constituição de espaços dialógicos, reflexivos, com o intuito de planejar e organizar estratégias para a implementação das diretrizes da Educação Especial junto aos professores e demais profissionais da comunidade escolar, a fim de assegurar o direto à escolarização desses estudantes. 
Ainda que as diretrizes de Educação Especial possam colaborar para a organização de sistemas educacionais inclusivos, elas se mostram apenas como documentos norteadores da política. Desse modo, a forma como ocorre sua materialização perpassa, ainda, pelos interesses dominantes da sociedade, pelo entendimento dos gestores dos sistemas de ensino, assim como pela compreensão da equipe diretiva e dos profissionais da educação como um todo, os quais têm a incumbência de sua efetivação no espaço escolar.

Embora os dizeres da minoria dos integrantes das equipes diretivas apontem para um entendimento menos individualizado e isolado do processo de escolarização dos estudantes público alvo da Educação Especial, não foi possível identificar uma abordagem crítica em que a Educação Especial seja compreendida como integrante da Educação Regular que se desenvolve em um sistema político, econômico e cultural marcado pela dialética inclusão/exclusão.

Pode-se inferir que, em parte, essa compreensão crítica não é favorecida pelo modo como hoje os espaços e tempos das escolas estão organizados. A forma como a escola se organiza não pode ser desvinculada de seu todo correspondente, isto é, a organização social e econômica da qual faz parte - nesse caso, um sistema capitalista e tecnológico, no qual as relações e as jornadas de trabalho são reguladas pelo capital e marcadas pela falta de "[...] tempo para o desenvolvimento intelectual, para o livre exercício do corpo e do espírito. O capital monopoliza o tempo que o desenvolvimento e equilíbrio do corpo em perfeita saúde exigem”. (MARX, 2013, p. 103)

\section{CONSIDERACְ̃̃ES FINAIS}

A partir das analises realizadas neste artigo, é possível compreender que por mais que as diretrizes de Educação Especial sejam importantes para a organização de sistemas educacionais inclusivos, elas se apresentam como um documento orientador da política. Assim, o modo como acontece sua efetivação perpassa, ainda, pelos interesses dominantes da sociedade, pela compreensão dos gestores dos sistemas de ensino, assim como pelo entendimento da equipe diretiva e dos profissionais da educação como um todo, os quais têm a incumbência de sua materialização no âmbito escolar.

Nessa direção, ao analisar as compreensões das equipes diretivas escolares sobre o serviço de AEE, foi possível identificar três focos de entendimentos: 1) foco no público-alvo da EE; 2) foco no local de atendimento (Sala de Recursos Multifuncionais); e, 3) 
foco no processo de escolarização como um todo. Pôde-se evidenciar que, em sua maioria, os participantes desta pesquisa restringiram sua compreensão sobre o AEE ao estudante com deficiência ou à Sala de Recursos Multifuncionais e ao professor especializado, indicando uma compreensão setorizada e individualizada do serviço, por parte das equipes diretivas escolares, o que pode fragilizar o processo de escolarização do estudante público-alvo da Educação Especial, assim como, sua permanência na escola.

Restringir o entendimento sobre o AEE ao estudante com deficiência ou à Sala de Recursos Multifuncionais e ao professor especializado pode indicar, ainda, uma compreensão descontextualizada e desarticulada sobre o serviço no âmbito da escola, indicado que se mantém, nos espaços escolares, uma visão de segregação que responsabiliza a Sala de Recursos Multifuncionais, bem como o professor especializado, pela aprendizagem do estudante público-alvo da EE.

As sete equipes diretivas pesquisadas apresentaram necessidades diferentes quanto à viabilização do AEE em seus espaços escolares e que necessitam ser levadas em conta. Contudo, em relação às compreensões das equipes diretivas no que concerne ao AEE, identificou-se um ponto em comum em suas falas, que diz respeito a indícios de uma carência de um maior conhecimento das leis, diretrizes, orientações e teoria sobre a Educação Especial.

Tal constatação pode ser percebida quando se observa que das sete escolas pesquisadas, somente duas possuem o AEE em funcionamento, as demais, exceto a ED5, indicam não ofertar o serviço e não encaminhar o estudante para ser atendido em outra escola, o que pode revelar uma precariedade no processo de escolarização dos estudantes público-alvo da EE.

Por conseguinte, uma mudança acerca dessa visão apresentada sobre o AEE, nos dizeres das equipes diretivas, se mostra uma tarefa complexa, considerando que a escola pública brasileira tem enfrentado muitos desafios, quando se trata do ensino, considerando a diversidade cada vez maior de estudantes, assim como as proposições políticas da Educação que permeiam o cotidiano das escolas, as quais parecem estar fundamentadas e organizadas em procedimentos normativos, avaliativos, em que predominam a competitividade e individualidade nas relações entre os indivíduos da mesma escola em detrimento de um trabalho coletivo. Considera-se, nesse sentido, que o AEE, hoje, parece ser a expressão mais evidente da (des)articulação entre a Educação Regular e a EE. 
Uma forma de contribuir e favorecer mudanças de concepções e práticas seria buscar parceira com as Instituições Públicas de Ensino Superior, sediadas no município ou em seu entorno, considerando a constituição e o fortalecimento de uma rede de apoio para a realização de formações que contemplem um aprofundamento teórico e prático na área da Educação e da Educação Especial, para os profissionais da educação da Rede pesquisada. Compreende-se, assim, que essa ação poderia contribuir para repensar e ressignificar a PNEE-PEI e o AEE na rede municipal de ensino.

Por fim, nesse momento histórico, econômico, político e social de incertezas em que se vive atualmente, avista-se discutir o papel das equipes diretivas escolares na implementação e viabilização do AEE pode ser uma oportunidade de criar espaços e tempos de discussão e reflexão. Com o objetivo de propiciar a participação efetiva de professores e demais profissionais da educação no planejamento, organização, discussão e implementação das estratégias e diretrizes da Educação Regular e da Educação Especial de modo articulado, tendo em vista o direito de aprender de todos os estudantes.

Em meio a esses apontamentos, chega-se ao final dessas considerações. Contudo, entende-se que esse estudo não se conclui aqui, mas pode possibilitar novos caminhos e outros direcionamentos que poderão ser suscitados com base no que foi revelado a partir das compreensões das equipes diretivas escolares sobre o serviço de Atendimento Educacional Especializado. Um desses caminhos é realizar pesquisas de cunho etnográfico que possibilitem observar, no cotidiano das escolas, como se dão as (des)articulações entre Educação Especial e Educação regular.

\section{REFERÊNCIAS}

ARAÓZ, S.M.M. de. Inclusão de alunos com deficiência múltipla: análise de um programa de apoio. 2010. 185 f. Tese (Doutorado em Educação Especial) - Universidade Federal de São Carlos, São Carlos, SP, 2011.

BOAVENTURA, R. S. A Gestão Escolar Na Perspectiva Da Inclusão. 122 f. Dissertação de Mestrado. Universidade do Oeste Paulista. Presidente Prudente - SP. 2008.

BRASIL. Ministério da Educação. Secretaria da Educação Especial. Política Nacional de Educação Especial na Perspectiva da Educação Inclusiva. Brasília, DF, 2008.

BRASIL. Conselho Nacional de Educação. Câmara de Educação Básica. Resolução CNE/ CEB n. ${ }^{\circ}$ 4, de 2 de outubro de 2009. Institui Diretrizes Operacionais para o Atendimento Educacional Especializado na Educação Básica, modalidade Educação Especial. Diário Oficial da União, 5 de outubro de 2009. 
BARDIN, L. Análise de conteúdo. Lisboa: Edições 70, 1977.

EFFGEN, A. P. S. Educação especial e currículo escolar: possibilidades nas práticas pedagógicas cotidianas. 221 f. Dissertação de Mestrado. Universidade Federal do Espírito Santo. Vitória. 2011.

FRANÇA, M. G. No entrelaçar das complexas tramas políticas e sociais da inclusão escolar: o trabalho do professor de educação especial. 356 f. Dissertação (Mestrado em Educação)- Faculdade de Educação, Universidade Federal do Espírito Santo. Vitória, ES. 2008.

FRANCO, M. L. P. B. Análise de conteúdo. $4^{\text {a }}$ ed. Brasília: Liber Livro, 2012.

FREIRE, Paulo. Pedagogia da Esperança: um encontro com a pedagogia do oprimido. Rio de Janeiro: Paz e Terra, 1979.

FREITAS, L. C. Responsabilização, meritocracia e privatização: conseguiremos escapar do neotecnicismo? In: Seminário De Educação Brasileira. SBE, Campinas - SP. 2011. Anais Eletrônicos. Campinas, Centro de Estudos Educação e Sociedade, 2011. Disponível em: http://www.cedes.unicamp.br/seminarios3/luiz_freitas.pdf. Acesso em: 10 out. 2016.

FREITAS, L. C. A Internalização da Exclusão. Educ. Soc., Campinas, v. 23, n. 80, setembro/2002, p. 299-325. Disponível em http://www.cedes.unicamp.br. Acesso em: 10 out. 2016.

FREITAS, M. T. de A. A abordagem sócio-histórica como orientadora da pesquisa qualitativa. Cad. Pesquisa (online), n.116, p. 21-39, 2002.

FREITAS, S. N. O direito à educação para a pessoa com deficiência: considerações acerca das políticas públicas. In: BAPTISTA, C. R.; JESUS, D. M. de (org.). Avanços em políticas de inclusão: o contexto da educação especial no Brasil e em outros países. $2^{\mathrm{a}}$ ed. Porto Alegre: Mediação, 2011.

FUCK, A. H. O atendimento educacional especializado nas salas de recursos multifuncionais na concepção dos professores da sala comum. Dissertação de Mestrado. 190 f. Universidade da Região de Joinville, Joinville. 2014.

GATTT, B.; ANDRÉ, M. A relevância dos métodos de pesquisa qualitativa em Educação no Brasil. In: WELLER, W.; PFAFF, Nicolle (org.). Metodologia da pesquisa qualitativa em educação: teoria e prática. $2^{\mathrm{a}}$ ed. Petrópolis, RJ: Vozes, 2013.

GARCIA, R. M. C. Política de educação inclusiva e trabalho pedagógico: uma análise do modelo de educação especial na educação básica. Anais. IV Seminário Nacional de Pesquisa em Educação Especial: Conhecimento \& Margens. Gramado: RS, 2008.

GUARESCHI, P. A. Pressupostos psicossociais da exclusão: competitividade e culpabilização. In: SAWAIA, B. As artimanhas da exclusão: análise psicossocial e ética da desigualdade social. $10^{\mathrm{a}}$ ed. Petrópolis, RJ: Vozes, 2010.

KASSAR, M. de C. M.; MELETTTI, S. M. F. Análises de Possíveis Impactos do Programa Educação Inclusiva: Direito à Diversidade. Ci. Huma. e Soc. em Rev., RJ, EDUR, v. 34, n.12, p. 49-63, 2012. 
LIBÂNEO, J. C. Organização e gestão da escola: teoria e prática. Revista e ampliada. Goiânia: MF Livros, 2015.

MARTINS, L. de A. R. Por uma escola aberta às necessidades do aluno. Temas sobre desenvolvimento, São Paulo, v. 10, n. 55, p. 28-34, 2001.

MARTINS, J. de S. O falso problema da exclusão e o problema social da inclusão marginal. In: MARTINS, J. de S. Exclusão social e a nova desigualdade. São Paulo: Paulus, 1997.

MARX, K. O capital. Tradução e condensação de Gabriel Deville. $3^{\mathrm{a}}$ ed. $2^{\mathrm{a}}$ reimp. Bauru, SP: EDIPRO, 2013.

MELETTI, S. M. F. Diferenças e diferentes aspectos psicossociais da deficiência. In: MELETTTI, S. M. F., KASSAR, M. de C. M. Políticas Públicas, escolarização de alunos com deficiência e a pesquisa educacional. Campinas. Mercado das Letras: 2013.

MICHELS, M. H.. A formação de professores de educação especial na UFSC (19982001): ambiguidades estruturais e a reiteração do modelo médico-psicológico. 2004. Tese (Doutorado em Educação) - Programa de Pós-Graduação em Educação: história, política, sociedade, Pontifícia Universidade Católica de São Paulo, São Paulo, 2004.

MICHELS, M. H. Gestão, formação docente e inclusão: eixos da reforma educacional brasileira que atribuem contornos à organização escolar. Revista Brasileira de Educação v. 11 n. 33 set./dez. 2006.

PARO, V. H. Crítica da Estrutura da Escola. São Paulo: Cortez. 2016.

PARO, V. H. Eleições de diretores: a escola pública experimenta a democracia. São Paulo: Xamã, 2003.

PLETSCH, M. D. A dialética da inclusão/exclusão nas políticas educacionais para pessoas com deficiências. Revista Teias v. 12, n. 24, p. 39-55. jan./abr. 2011.

PLETSCH, M. D. Repensando a Inclusão Escolar: Diretrizes políticas, práticas curriculares e deficiência intelectual. RJ. NAV: EDUR, 2010.

ROSSATO, S. P. M.; LEORNADO, N. S. T. Queixa Escolar e Educação Especial. In: BARROCO. S. M. S.; LEORNADO, N. S. T.; SILVA, T. dos S. A. da. Educação Especial e Teoria Histórico-Cultural: Em defesa da humanização do homem. Maringá: Eduem. 2012.

ROCHA. L. M. da. A Gestão da Educação Especial nos Municípios da área Metropolitana Norte de Curitiba: Uma Análise Decorrente da Política Nacional de Educação Especial na Perspectiva da Educação Inclusiva. 182 f. Dissertação de Mestrado. Universidade Federal do Paraná. Curitiba. 2016.

ROCHA, Vania Meneghini da. A Educação Especial nos Institutos Federais: O que dizem os Planos de Desenvolvimento Institucionais? Dissertação de Mestrado. 2016. 162 f. Universidade da Região de Joinville. Joinville.

SILVEIRA. S. M. P.. A gestão para a inclusão: uma pesquisa-ação colaborativa no meio escolar. Tese (Doutorado). 277f. Universidade Federal do Ceará. Fortaleza. 2009. 
SANTOS, R. R. da S.. Gestão Escolar para uma escola inclusiva: conquistas e desafios. Dissertação de Mestrado. 90 f. Universidade do Oeste Paulista. Presidente Prudente. 2011.

UNICEF. Declaração Mundial sobre Educação para Todos. Jomtien, 1990. Disponível em: <http://www.unicef.org/brazil/pt/resources_10230.htm>. Acesso em: 13. mar. 2016.

UNESCO. Declaração de Salamanca Sobre Princípios, Políticas e Práticas na Área das Necessidades Educativas Especiais. 1994. Disponível em: < http:// portal.mec.gov. br/seesp/arquivos/pdf/salamanca.pdf >. Acesso em: 13 mar. 2016.

VASCONCELLOS, C. Coordenação do Trabalho Pedagógico: do projeto político pedagógico ao cotidiano de sala de aula. São Paulo: Libertad, 2013.

VASQUES, C. K. O diagnóstico e a Escolarização de alunos com transtornos globais do desenvolvimento. In: BAPTISTA, C. R. (org.). Escolarização de alunos com deficiências: configurações nas políticas de inclusão escolar. São Carlos: Marquezine \& Manzini, 2015.

VEIGA-NETO, A. Incluir para excluir. In: VEIGA-NETO, A.; LARROSA, J.; SKLIAR, C. Habitantes de Babel: políticas e poéticas da diferença. $2^{\mathrm{a}}$ ed. Belo Horizonte: Autêntica Editora, p. 105-118, 2011.

\section{NOTAS}

${ }^{1}$ Público-alvo da Educação Especial: é utilizado nesse artigo para se referir aos estudantes com deficiências, transtornos globais do desenvolvimento e altas habilidades/superdotação, preconizados na PNEE-EI e nas diretrizes da EE.

${ }^{2}$ Utilizou-se a abreviação ED1 para indicar os dados referentes a Equipe diretiva 1, e ED2 para indicar a Equipes Diretiva 2 e, assim sucessivamente.

${ }^{3}$ Segundo o documento oficial do município pesquisado que detalha as atribuições dos profissionais do magistério, o Monitor de inclusão é o profissional que auxilia o estudante público-alvo da EE, nas questões pedagógicas, bem como, nos aspectos de cuidado, assistência e socialização, no âmbito escolar.

${ }^{4}$ Segundo Meletti (2013, p. 27) inclusão precária significa "se inserir em um espaço social já existente e essencialmente excludente”. Para Martins (1997), todas as pessoas estão incluídas na sociedade, contudo, podem estar incluídas de forma perversa, subalterna, à margem da sociedade.

Submetido: 30/12/2016

Aprovado: 04/12/2017

Contato:

Neusa Denise Marques de Oliveira Rua do Empreendedor 555 Apto 801ª

Bloco D1, Bairro Santa Lídia

Camboriú|SC | Brasil

CEP 88.341-240 